\title{
EL PUEBLO DE LA REVOLUCIÓN. LAS ORGANIZACIONES ARMADAS ARGENTINAS EN LOS AÑOS SETENTA ${ }^{1}$
}

\author{
Daniela Slipak ${ }^{2}$
}

\begin{abstract}
Taking Claude Lefort's arguments as a base, this article analyzes practices and representations of the two most important military organizations of Argentina, Montoneros and the Partido Revolucionario de los Trabajadores-Ejército Revolucionario del Pueblo (PRT-ERP). Those non state organizations arose during the dictatorship governments of the Revolución Argentina (1966-1973) and incorporated militants to become the two insurgent groups with greater impact and political visibility of the time. A few years later, after the rule of another dictatorship government, the so called Proceso de Reorganización Nacional (1976-1983), Montoneros and the PRT-ERP felt in a breakdown and desestructration process. Studying documents, publications, statements and practices of Montoneros and the PRT-ERP, on one hand, this article questions about how this groups represented their political internal space and how they faced diversity and division of social relations. On the other hand, we tend to show the potential of Lefort's reflections to understand the experience of armed groups in Latin America during the second half of twentieth century.

Keywords: Claude Lefort - dictatorship - armed groups -Latin America.
\end{abstract}

\section{Introducción}

Como señala Miguel Abensour, la interpretación de Claude Lefort sobre el totalitarismo fue desplazándose a lo largo de sus escritos. Los primeros argumentos, expuestos más cabalmente en el "El totalitarismo sin Stalin", subrayaron los rasgos y dinámicas del Partido, definido como una casta burocrática contrarrevolucionaria que controla todos los ámbitos de la sociedad, sostiene un nuevo sistema de explotación, y se escinde del proletariado, actor al cual en ese entonces Lefort seguía confiando la verdadera empresa revolucionaria. Dicha interpretación se articuló desde el universo marxista y buscando un socialismo antiburocrático, aunque es cierto, y no debería dejar de subrayarse,

\footnotetext{
${ }^{1}$ Dossiê Claude Lefort: esse texto é parte do dossiê publicado a partir das comunicações realizadas no Colóquio Internacional Claude Lefort: a invenção democrática hoje, realizado na Universidade de São Paulo entre os dias 13 e 16 de outubro de 2015.

2 Doctora en Estudios Políticos (EHESS-UBA), investigadora CONICET-UNSAM. Agradezco a Matías Sirczuk los comentarios y sugerencias realizados a una versión preliminar de este artículo.
} 
que con ella Lefort iba más allá de las aproximaciones críticas que desde la izquierda francesa se venían haciendo al régimen de la Unión Soviética. ${ }^{3}$

La ruptura con el grupo Socialisme on Barbarie en 1958, el distanciamiento respecto del marxismo, el encuentro con la obra de Nicolás Maquiavelo y una idea de la división como elemento constitutivo de lo político permitieron dar una nueva vuelta a la argumentación. Ello no implicó un viraje completo en relación a los escritos precedentes, puesto que, como Lefort mismo afirmó, sus primeros análisis le dieron las herramientas para franquear sus límites ${ }^{4}$ (por ejemplo, es de notar que en ellos ya aparece la alusión al totalitarismo como forma de sociedad, o la consustanciación entre Estado y sociedad, o la idea de una simulación fantástica de la unidad). Pero, pensado bajo esta nueva luz, el totalitarismo permitía dar cuenta de una sociedad que negaba fantásticamente la división, inaugurando una puesta en forma, en sentido y en escena particulares. Dicha forma sólo podía ser advertida desde una apreciación de la democracia como la inauguración de una dinámica imposible de restringir a un conjunto de instituciones o derechos positivos, y cuyo significado se revelaba sólo en el registro simbólico. ${ }^{5}$ Desde allí, Lefort señalaba las representaciones que atravesaban la experiencia totalitaria. Por un lado, la imagen del cuerpo que articulaba una lógica de identificación entre la sociedad, el proletariado, el Partido, sus dirigentes y el Egócrata. Es decir, una concepción de la sociedad como un cuerpo plausible de ser encarnado por el Partido y fundamentalmente por el Egócrata, figura que, pretendiendo absorber toda la sustancia de lo social, se erigía simultáneamente como su cabeza. Una incorporación que evocaba, pero se distanciaba de la encarnación trascendente del príncipe propia de la matriz teológico-política. Si ésta enviaba a un más allá, aquélla se encerraba en la inmanencia de lo social. Por otro lado, la lógica totalitaria implicaba simultáneamente una fusión de las instancias del poder, de la ley y del saber. Esto es, a la lógica de identificación se le añadía la de indistinción. Como recuerda Miguel Abensour, el Egocrata no sólo decía "la sociedad, soy yo" sino también "la ley, soy yo" "el saber, soy yo". Ello suponía una representación del pueblo como un sujeto plenamente figurado y homogéneo, un Pueblo-Uno, cerrado sobre sí mismo y transparente, que borraba la división y heterogeneidad internas, situándolas por fuera del espacio comunitario en esos otros maléficos, parásitos que debían limpiarse vía el procedimiento de la profilaxis social. Por último, esta imagen del cuerpo se tensionaba con otra imagen, la de la máquina, que evidenciaba una pretensión de control y organización del conjunto de los hombres,

\footnotetext{
3 LEFORT, Claude. Éléments d'une critique de la bureaucratie, Paris, Gallimard, 1971; ABENSOUR, Miguel. "Réflexions sur les deux interprétations du totalitarisme chez C. Lefort", en HABIB, Claude y MOUCHARD, Claude. (dir.), La démocratie à l'cuvre. Autour de Claude Lefort, París, Esprit, 1993, pp. 79-136.

${ }^{4}$ LEFORT, Claude. Ob. cit., 1971.

${ }^{5}$ Véase FLYNN, Bernard. Leforty lo político, Buenos Aires, Prometeo, 2008.

${ }^{6}$ ABENSOUR, Miguel. Ob. Cit., p. 113.
} 
como si se tratara de una materia prima amorfa y moldeable por un ingeniero o constructor social. De allí que los "hombres que sobran" fueran representados por el fantasma del parásito orgánico o el del saboteador del funcionamiento mecánico de la organización social. $^{7}$

De este modo, organicismo, artificialismo, uniformidad, indistinción e incorporación de lo social constituían las imágenes, metáforas y fantasmas que atravesaban el totalitarismo. Figuras que, lejos de ser epifenómenos secundarios, establecían los principios ordenadores de la coexistencia. En sus últimos escritos, Lefort se dedicó a "complicar" un poco más la interpretación, iluminando, por ejemplo, lo dispositivos jurídicos del totalitarismo, como la "perversión de la ley" sostenida en una relación dual entre acusador/acusado. No obstante, más allá de ésta como de otras "complicaciones", lo cierto es que a grandes rasgos Lefort mantuvo los argumentos esbozados precedentemente. $^{8}$

Es a partir de estas reflexiones que pretendo repensar las organizaciones armadas argentinas en la década del setenta, surgidas al calor de los cambios internacionales del marxismo, pero también de un conjunto de acontecimientos y transformaciones de carácter nacional. Para analizarlas, propongo retomar las representaciones totalitarias recién delineadas, pero escindiéndolas, si se quiere, de la gran matriz simbólica que fue el totalitarismo. Es decir, observaré cómo dichos fantasmas juegan en coyunturas no tan claramente totalitarias y en fuerzas políticas que no accedieron al Estado, si bien, evidentemente, se vieron empapadas por los debates sucedidos al interior del mundo de las izquierdas una vez caido el estalinismo. En suma, quisiera apropiarme de las imágenes y lógicas con las cuales Lefort se refirió al totalitarismo a modo de manchas que habitan, de manera fragmentada y tensa, en latitudes y periodos disímiles. ${ }^{9}$ Particularmente, me concentraré en las dos organizaciones que tuvieron mayor importancia en la escena política argentina, el Partido Revolucionario de los Trabajadores-Ejército Revolucionario del

\footnotetext{
7 LEFORT, Claude. Un homme en trop. Réflexions sur L'Archipel du Goulag'. París, Éditions du Seuil, 1976; L'invention démocratique. Les limites de la domination totalitaire. París, Fayard, 1981.

${ }^{8}$ LEFORT, Claude. La complication. Retour sur le communisme, París, Fayard, 1999.

${ }^{9}$ En cierta medida, este ejercicio está planteado por el propio Lefort. Si bien establece la existencia de una radical mutación simbólica entre democracia y totalitarismo, no hace sino advertir acerca de la raigambre democrática del último (por ejemplo, la representación de la máquina lleva al extremo la creencia iluminista en la autodeterminación y la racionalidad). Además, en diversos ensayos, cuestiona la lógica del Partido Comunista en Francia o, incluso, algunos elementos del pensamiento leninista. Es decir, de algún modo, invita a bosquejar una zona gris entre democracia y totalitarismo, más allá de sus inconfundibles y sensibles fronteras. Una propuesta de radicalización de estas zonas grises puede encontrarse en PLOT, Martín. "Teología, estética y epistemología políticas en Lefort, Schmitt y Arendt", Documentos de Trabajo, Universidad de Belgrano, N²87, 2013.
} 
Pueblo (PRT-ERP) y Montoneros. Revisaré sus documentos, declaraciones y prácticas a fin de identificar sus lógicas de constitución y funcionamiento.

\section{El pueblo en el PRT-ERP y Montoneros}

Como ya numerosos estudios lo han señalado, el origen de dichas organizaciones estuvo marcado por diversas circunstancias: una larga historia de inestabilidad política nacional, que intercambió gobiernos militares y gobiernos constitucionales con proscripción del peronismo; la radicalización de la sociedad y la peronización de muchos sectores de izquierda en los años sesenta; los debates surgidos en los ámbitos católicos al calor del Concilio Vaticano II; la influencia de los procesos de descolonización en Asia y África; la circulación de las tesis de Jean Paul Sartre y Frantz Fanon; la popularidad del esquema foquista y el triunfo de la Revolución Cubana; los proyectos y las figuras de Camilo Torres y de Ernesto Che Guevara, cuyas muertes no opacaron las esperanzas en la revolución; entre tantas más. ${ }^{10}$ En este marco, a fines de los sesenta y comienzos de los setenta, se articularon en Argentina diversos grupos armados, de raigambre peronista o marxista/guevarista, cuyo propósito fue, en principio, establecer guerrillas rurales o urbanas. Algunos de ellos fueron ganando adeptos y simpatizantes, establecieron alianzas con otros actores de la coyuntura, y terminaron por convertirse en grandes organizaciones político-militares de alcance nacional, que conjugaron actividades armadas (como el asesinato de militares, policías, empresarios y dirigentes sindicales) con una amplia política de superficie en barrios, fábricas, universidades y colegios. Sus actividades se publicitaron en distintos órganos de prensa, cuya tirada fue desde los 10.000 a los 100.000 ejemplares. Al interior de la galaxia marxista, la organización que tuvo mayor presencia fue el PRTERP, que terminó de consolidarse en 1970, luego de 5 años de escisiones y reagrupaciones. Complementó un Partido revolucionario de cuadros con un sector militar. Levantó la bandera del marxismo-leninismo, a la cual agregó la defensa de la guerra popular y prolongada maoísta, y algunos aspectos de las tesis guevaristas, sin dejar de adherir hasta 1973 a la IV Internacional. En el caso del peronismo, fue Montoneros el más resonante. Recibió afluentes de distintos grupos armados peronistas y de ámbitos católicos, sindicales, universitarios y estudiantiles. A diferencia del PRT-ERP, ocupó, aunque sólo por contadas semanas, cargos en gobernaciones provinciales, ministerios nacionales y el Parlamento,

\footnotetext{
${ }^{10}$ Sobre estos procesos, véanse JAMES, Daniel. (dir.) Violencia, proscripción y autoritarismo (1955-1976), t. IX de la Nueva Historia Argentina, Buenos Aires, Sudamericana, 2003; ALTAMIRANO, Carlos. Peronismo y cultura de izquierda [2001], Buenos Aires, Siglo XXI, 2013; LANUSSE, Lucas. Montoneros. El mito de sus 12 fundadores, Buenos Aires, Vergara, 2007; CALVEIRO, Pilar. Política y/o violencia. Una aproximación a la guerrilla de los años setenta [2005] Buenos Aires, Siglo XXI, 2012; entre muchísimos más.
} 
gracias a su incorporación momentánea en el Movimiento Peronista. La llegada de Perón al país después de un largo exilio, y las tensiones crecientes con él y con otros actores peronistas, los apartaron de dichos ámbitos. Desde mediados de los setenta, ambas organizaciones fueron perdiendo su caudal, sobre todo debido a la feroz represión del gobierno de la viuda de Perón, María Estela Martínez, y al terror desplegado por el gobierno militar establecido en marzo de 1976.

En general, tanto el PRT-ERP como Montoneros han sido estudiados atendiendo al uso de la violencia armada, a la estructura organizativa y al despliegue territorial. ${ }^{11}$ Pocos estudios se abocan a indagar sus aspectos identitarios, sus representaciones, sus discursos, su disciplina y sus dispositivos jurídicos. ${ }^{12}$ Es precisamente observando dichas cuestiones que los argumentos trazados por Lefort resultan iluminadores. Es cierto que ninguna de estas organizaciones defendió el estalinismo ni logró arribar al Estado. Además, ninguna fue, evidentemente, un totalitarismo pleno que sembró el horror y el terror como en otras latitudes. No obstante, creo que es posible encontrar en ellas, a modo de manchas fragmentarias, no necesariamente coherentes ni lineales, algunos de los fantasmas con los cuales Lefort comprendió el totalitarismo.

Comienzo por el PRT-ERP. La imagen de lo social como un cuerpo recorrió sus redes de militancia de disímiles maneras: para nominar a sus disidencias, para catalogar a sus adversarios, y para relatar su historia. El PRT-ERP se terminó de constituir en el V Congreso del Partido de julio de 1970 bajo el liderazgo de Roberto Santucho y con la convicción de que era hora de consolidar la vía armada a través de un "ejército popular". Ello ocurrió tras la salida en 1968 de la fracción liderada por Nahuel Moreno, conocida como PRT-La Verdad, la cual consideraba que la situación del país reclamaba no tanto el inmediato pasaje a las armas sino el reforzamiento de la actividad sindical y la reactivación de las huelgas obreras. Luego de la separación entre ambos sectores, los distintos congresos, documentos y la prensa del PRT-ERP refirieron a la fracción de Moreno como un "virus", el "virus morenista", como un "gas venenoso", y afirmaron que era necesario "inmunizar" al Partido de dicha infección, asociada a los intereses "burgueses" o "pequeño-burgueses", a la ausencia de moral de combate y a falta de iniciativa. Se repitió

\footnotetext{
11 LANUSSE, Lucas. ob. cit; Richard Gillespie, Soldados de Perón. Los Montoneros [1982], Buenos Aires, Grijalbo, 1987; POZZI, Pablo. "Por las sendas argentinas: El PRT-ERP, la guerrilla marxista, Buenos Aires, Imago Mundi, 2004.

12 En el caso del PRT-ERP, véase CARNOVALE, Vera. Los combatientes. Historia del PRT-ERP, Buenos Aires, Siglo XXI, 2011; sobre Montoneros, veáse mi trabajo Las revistas montoneras. Cómo la organización construyó su identidad a través de sus publicaciones, Buenos Aires, Siglo XXI, 2015.
} 
muchas veces que para lograr la prometida revolución y mantener la cohesión del Partido, se lo debía resguardar de dicha "enfermedad". ${ }^{13}$

También estas representaciones aparecieron en el trato, más o menos antagónico, hacia otros actores de la coyuntura. Un recuadro publicado en el número 13 del órgano de difusión del ERP, Estrella Roja, advirtió que las fuerzas represivas eran "los enemigos del pueblo" y que actuaban como "gusanos, parásitos de nuestro pueblo que no trabajan y que se comen el presupuesto nacional”. Este organicismo tiñó, a su vez, la apreciación de otras fuerzas como el tradicional Partido Comunista (PC) o la organización Montoneros. Criticando el apoyo que éstos dieron a los gobiernos peronistas del periodo, el documento "Poder burgués y poder revolucionario" firmado por Santucho en agosto de 1974 señaló que el PC sufría un "cáncer reformista" y que el populismo defendido por Montoneros era una "enfermedad política e ideológica" y que debía ser "extirpada" del campo popular. Agregó que había que "curar a las organizaciones y compañeros afectados" por estas enfermedades. ${ }^{14}$

Todas estas afirmaciones fueron acompañadas por un permanente énfasis en la disciplina que debían seguir los cuadros del Partido. Los documentos, estatutos y reglamentaciones partidarios enfatizaron la pretensión de consolidar células homogéneas, controladas jerárquicamente. Reclamaron para el Partido una "homogeneidad proletaria de profesionales revolucionarios" y una "disciplina de hierro". Mencionaron escasamente la dimensión de la discusión democrática propia del esquema del centralismo democrático leninista. Por el contrario, subrayaron la necesidad de reforzar la cohesión y la unidad partidaria. Tal como sucedió en otros grupos insurgentes, decretaron que los militantes debían consagrar la totalidad de sus actividades, incluso las sexuales y familiares, a la causa común; es decir, que la "entrega" debía ser total. Al respecto, citaban la conocida frase de Guevara: "no hay vida fuera de la revolución". ${ }^{15}$ Todas estas obligaciones fueron controladas por la dirección partidaria, con sanciones más o menos informales como la despromoción, el arresto en "cárceles del pueblo", o la expulsión. La crítica o el incumplimiento de la normativa fue catalogado en términos de un desvío "pequeño burgués", de una conducta "individualista", acusada de anteponer la persona individual al Partido. En fin, lo que quisiera remarcar es que esta disciplina destinada a conformar un Partido homogéneo tampoco estuvo exenta del fantasma del cuerpo. Al respecto, el documento "Moral y proletarización", afirmaba en 1972: "El individualismo es una

\footnotetext{
${ }^{13}$ Véase por ejemplo "Resoluciones del V Congreso", 28 y 29 de julio de 1970, en DE SANTIS, Daniel. (comp.), ;A vencer o morir! PRT-ERP Documentos, Colectivo Amauta, v. 1, pp. 96-123.

${ }^{14}$ Estrella Roja, n¹3, junio de 1972, contratapa; SANTUCHO, Roberto. "Poder burgués y poder revolucionario", agosto de 1974, en DE SANTIS, Daniel. op. cit., v. 2, pp. 190-213.

${ }^{15}$ GUEVARA, Ernesto. "El socialismo y el hombre en Cuba". Marcha, Montevideo, marzo de 1965.
} 
verdadera gangrena que continuamente destruye lo que construimos (...) [es] el verdadero cáncer de cualquier organización". ${ }^{16}$

Por su parte, el número 86 del órgano de difusión del PRT, El Combatiente, afirmó sobre la dinámica al interior del Partido:

Cuando las diferencias se vuelven irreductibles y devienen en duros enfrentamientos de tipo personal (...) esto refleja un interés social, un punto de vista no proletario, que tiene su base material en intereses burocráticos o pequeño burgueses (...) es necesario resolver[lo] mediante una enérgica liquidación de estas corrientes no proletarias: primero derrotarlas ideológica y políticamente, para así 'curando el mal, tratar de salvar al enfermo' y en caso de persistir en sus posiciones antiobreras, expulsarlas sin contemplaciones del seno de la organización como se extirpa un tumor para que no afecte a la mayoría sana del organismo. ${ }^{17}$

Ahora bien, aunque esta imagen del cuerpo y la idea de un pueblo homogéneo curado de divisiones y diferencias internas atravesaron las aspiraciones del PRT-ERP, dando forma a las prácticas y creencias militantes, lo cierto es que dicha organización no desplegó la lógica de identificación totalitaria también señalada por Lefort entre la sociedad, el Partido, la dirigencia y el Egócrata. En sus afirmaciones, el PRT-ERP mantuvo, más o menos fuertemente, la clásica tesis leninista enunciada en el Qué hacer del Partido de vanguardia como agente externo que debía, "desde afuera", traer la conciencia revolucionaria al proletariado. Ello lo llevó a posicionarse como un actor central para liderar la "guerra popular", que debía tener un estrechísimo vínculo con el proletariado, pero manteniendo a fin de cuentas cierta distancia para ejercer "desde afuera" la actividad de dirección y para despertar la conciencia revolucionaria. De allí que ni en su prensa ni en sus documentos partidarios, el PRT-ERP se confundiera con el "pueblo". Es decir, a pesar de que Santucho demandó la vinculación con las masas y la "proletarización", no afirmó "el pueblo, soy yo" o "la sociedad, soy yo", tal como Lefort recuerda en el caso de los Egócratas. En definitiva, quisiera subrayar que el respeto -aunque con vaivenes, como señala Carnovale- por el esquema leninista de la vanguardia externa al proletariado hizo que

${ }^{16}$ ORTOLANI, Luis. (seud. Julio Parra), "Moral y proletarización”. 1972 en Politicas de la Memoria, no 5, 2014.

${ }^{17}$ El Combatiente, n86, 17 de agosto de 1974, p. 8. Sobre la disciplina en el PRT-ERP, véase CARNOVALE, Vera. ob. cit. 
el PRT-ERP mantuviera cierta distancia, impidiendo esa encarnación inmanente, esa ficción de consustanciación o fusión. ${ }^{18}$

Distinta fue la situación de la organización Montoneros, más alejada del marxismoleninismo y más cercana a la tradición peronista. Es cierto que no recurrió explícitamente a la metáfora orgánica ni evocó la idea del cuerpo que debía curarse de sus parásitos, más propia de la tradición de izquierda de ese entonces. Pero sí fue atravesada por esa lógica de identificación intrínseca al totalitarismo. En su prensa, construyó su historia, sus orígenes y alteridades aseverando que ella era la heredera de las luchas populares del siglo XX. Trazó una línea de continuidad entre las huelgas y sabotajes de los trabajadores de mediados de los años cincuenta, las movilizaciones populares como el Cordobazo de 1969, y las intervenciones armadas de las guerrillas de fines de los sesenta y comienzos de los setenta. Aunó esas disímiles intervenciones bajo la figura de un "pueblo combativo" reacio a todo dispositivo y procedimiento institucional liberal o republicano. Estableció que las elecciones y el debate parlamentario, en vez de conformar la voluntad ciudadana, no hacían sino pervertir y desviar la sustancia popular. Y al hacer todo esto se planteó como un actor estrechamente vinculado a dicha sustancia popular, mejor dicho, fusionado o confundido con ella. Por ejemplo, la revista montonera La Causa Peronista esbozó en agosto de 1974:

Porque la ofensiva y la fuerza está en manos del imperialismo y la oligarquía, y nosotros, el pueblo, sólo podemos resistir su escalada para dificultársela, para hacerles perder fuerza a cada paso. ${ }^{19}$

Unos meses antes, también la revista montonera El Descamisado había sentenciado:

Cuando Perón y el pueblo se juntan sólo triunfan Perón y el pueblo. Lo demás se resquebraja como tierra seca. [...] Eso le pasó a la burocracia [sindical] cuando por encima de ellos el Movimiento se unió desde sus bases tras un único objetivo: Perón. Perón entre nosotros, Perón con nosotros, Perón y el pueblo peronista. ${ }^{20}$

De este modo, Montoneros propuso al "pueblo" como una figura lineal y sustancial, renuente a las instituciones liberales, e incorporada a sus huestes. Una encarnación que clausuraba toda distancia, separación o desdoblamiento entre la

\footnotetext{
18 Carnovale muestra de qué modo el esquema de la vanguardia se tensionó en sentido inverso con la "proletarización”, deudora de las prácticas de diversos movimientos trotskistas y maoístas. Ob. cit., pp. 229250.

${ }^{19}$ La Causa Peronista, no 5, 6 de agosto de 1974, p. 3, [el destacado me pertenece].

${ }^{20}$ El Descamisado, no 16, 4 de septiembre de 1973, p. 2 [el destacado me pertenece].
} 
organización Montoneros, su Conducción Nacional y los sectores populares. En última instancia, una encarnación que hacía de Mario Firmenich, jefe simultáneo del Partido Montonero, del Ejército Montonero y del Movimiento Peronista Montonero desde 1976, el que incorporaba en sí la sustancia popular.

A la par de esta identificación, Montoneros concibió su organización como un espacio cerrado sobre sí mismo que rechazaba cualquier diferencia interior. Aunque presentó similitudes con el PRT-ERP, fue más allá: creó dos códigos jurídicos disciplinarios, las Disposiciones sobre la Justicia Penal Revolucionaria de 1972, y el Código de Justicia Penal Revolucionario de $1975 .{ }^{21}$ Con ellos, vedó la crítica, la disidencia, la insubordinación, y las penalizó -con mayor severidad que el PRT-ERP- con la despromoción, el traslado, el encierro en "cárceles del pueblo" y el fusilamiento. Exigió eficacia, obediencia, sacrificio y la entrega de todos los aspectos de la vida, incluso los familiares y sexuales. Con estas normativas, durante la década de existencia montonera, se establecieron, además de las sanciones informales, Tribunales Revolucionarios que castigaron la crítica, la diferencia o la duda con el proyecto común. Se buscó así moldear las redes militantes, como si se tratara de una masa amorfa a ser trabajada y construida por un ingeniero social. La conocida "arcilla maleable" de Guevara. ${ }^{22}$ En palabras de Étienne de La Boétie y Lefort, como si todos fueran uno, y no unos. ${ }^{23}$ Como si se tratara de esa fantástica máquina artificial, capaz de ser manejada mecánicamente y de funcionar eficazmente. Esta homogeneidad y unidad tuvo su correlato en las instituciones políticas que se pretendían. Un documento montonero de mediados de 1973 afirmó:

Para conducir un proceso revolucionario, es decir, para asumir la ofensiva estratégica en un proceso revolucionario se hace necesaria una gran acumulación de poder y la centralización del mismo a los efectos de conducirlo [...]. En el sistema demoliberal, esa acumulación y centralización del poder es una contradicción: pretender acumular y centralizar el poder es contradictorio con la Constitución Nacional que establece entre otras cosas la división formal del poder: poder legislativo, ejecutivo y judicial, y el poder de las armas por otro lado. ${ }^{24}$

\footnotetext{
21 Véase LENCI, Laura. "Justicia, política y violencia. Un análisis de los cuerpos normativos montoneros 1972-1975". Ponencia de las II Jornadas "Partidos Armados en la Argentina de los Setenta", San Martín, 2008.

22 GUEVARA, Ernesto. ob. cit.

${ }^{23}$ LA BOÉTIE, Étienne de. Discurso de la servidumbre voluntaria [1577]. Madrid, Trotta, 2008.

24 BASCHETTI, Roberto. Documentos 1973-1976, La Plata, De la Campana, 1997, vol. 1, p. 263.
} 
Por tanto, si bien Montoneros no recurrió a la metáfora corporal, tal como lo hizo el PRT-ERP, desplegó una lógica de identificación, coqueteó con la representación de la máquina, buscó la centralización del poder, y acentuó aún más la idea de un espacio cerrado a la diferencia, a la distinción, y a la división entre los hombres. Trazos que, como recuerda Lefort, sólo pueden ser borrados de manera fantástica y provisoria, puesto que son constitutivos, originarios e inerradicables de la dinámica social.

\section{Palabras finales}

En las páginas precedentes, recorrí distintos documentos, periódicos, estatutos y prácticas de los dos grupos armados argentinos más relevantes de la década del setenta. Su distancia con respecto a la Unión Soviética sobre la cual Lefort se concentra es, a todas luces, evidente: el PRT-ERP y Montoneros fueron espacios políticos que no llevaron hasta las últimas consecuencias las metáforas orgánicas o artificiales, ni la lógica de identificación e incorporación, ni la idea de un Pueblo-Uno. Por lo demás, no ocuparon las instituciones estatales. Tampoco plantearon, lo que no es un dato menor, esa cantidad horrorosa de "enemigos" y "hombres que sobran" de la sociedad estalinista y de otros comunismos asiáticos. No entablaron una nueva puesta en forma, en sentido y en escena. Ni fueron protagonistas de una radical mutación simbólica. No obstante, nada de esto niega que dichas organizaciones armadas se hayan visto encantadas, al decir de La Boetie, por varias de las imágenes que Lefort atribuyó al totalitarismo. Como lo manifestaron sus documentos y su prensa, la figura del cuerpo, el organicismo, la lógica de identificación y el artificialismo tiñeron sus prácticas. Considero, por tanto, que una lectura atenta de los escritos de nuestro autor, de su advertencia acerca de que el totalitarismo no es algo cerrado, sino que se sitúa en el corazón de nuestro tiempo, nos permite vislumbrar de qué manera esos fantasmas también fueron manchas que se expandieron, con mayor o menor intensidad, por fuera de un mundo evidentemente totalitario. 


\section{Referências bibliográficas}

ABENSOUR, Miguel. "Réflexions sur les deux interprétations du totalitarisme chez C. Lefort", en HABIB, Claude y MOUCHARD, Claude. (dir.). La démocratie à l'auvre. Autour de Claude Lefort. París, Esprit, 1993, pp. 79-136.

ALTAMIRANO, Carlos. Peronismo y cultura de izquierda [2001]. Buenos Aires, Siglo XXI, 2013.

BASCHETTI, Roberto. Documentos 1973-1976. La Plata, De la Campana, 1997, vol. 1, p. 263.

CALVEIRO, Pilar. Política y / violencia. Una aproximación a la guerrilla de los años setenta [2005]. Buenos Aires, Siglo XXI, 2012.

CARNOVALE, Vera. Los combatientes. Historia del PRT-ERP. Buenos Aires, Siglo XXI, 2011.

DE SANTIS, Daniel. (comp.) "Resoluciones del V Congreso", 28 y 29 de julio de 1970, A vencer o morir! PRT-ERP Documentos, Colectivo Amauta, v. 1, pp. 96-123.

El Combatiente. $\mathrm{n}^{\circ} 86,17$ de agosto de 1974, p. 8.

El Descamisado. n 16, 4 de septiembre de 1973, p. 2.

Estrella Roja. n¹3, junio de 1972, contratapa.

FLYNN, Bernard. Leforty lo politico. Buenos Aires, Prometeo, 2008.

GILLESPIE, Richard. Soldados de Perón. Los Montoneros [1982]. Buenos Aires, Grijalbo, 1987.

GUEVARA, Ernesto. "El socialismo y el hombre en Cuba". Marcha, Montevideo, marzo de 1965.

JAMES, Daniel. (dir.) Violencia, proscripción y autoritarismo (1955-1976). t. IX de la Nueva Historia Argentina, Buenos Aires, Sudamericana, 2003.

LA BOÉTIE, Étienne de. Discurso de la servidumbre voluntaria [1577]. Madrid, Trotta, 2008.

LANUSSE, Lucas. Montoneros. El mito de sus 12 fundadores. Buenos Aires, Vergara, 2007.

LEFORT, Claude. Éléments d'une critique de la bureaucratie. Paris, Gallimard, 1971.

Un homme en trop. Réflexions sur 'L'Archipel du Goulag'. París, Éditions du Seuil, 1976.

L'invention démocratique: Les limites de la domination totalitaire. París, Fayard, 1981. 
LEFORT, Claude. La complication. Retour sur le communisme. París, Fayard, 1999.

La Causa Peronista. n 5, 6 de agosto de 1974, p. 3.

LENCI, Laura. "Justicia, política y violência: Un análisis de los cuerpos normativos montoneros 1972-1975". Ponencia de las II Jornadas "Partidos Armados en la Argentina de los Setenta". San Martín, 2008.

ORTOLANI, Luis. (seud. Julio Parra), "Moral y proletarización”, 1972 en Políticas de la Memoria. no $5,2014$.

PLOT, Martín. "Teología, estética y epistemología políticas en Lefort, Schmitt y Arendt". Documentos de Trabajo, Universidad de Belgrano, N²87, 2013.

POZZI, Pablo. "Por las sendas argentinas: El PRT-ERP, la guerrilla marxista, Buenos Aires, Imago Mundi, 2004.

SANTUCHO, Roberto. "Poder burgués y poder revolucionario". agosto de 1974, en Daniel De Santis (Comp.). A vencer o morir! PRT-ERP Documentos. Colectivo Amauta, v. 2, pp. 190-213.

SLIPAK, Daniela. Las revistas montoneras. Cómo la organización construyó su identidad a través de sus publicaciones. Buenos Aires, Siglo XXI, 2015. 